\title{
Effects of reduced dissolved oxygen concentrations on physiology and fluorescence of hermatypic corals and benthic algae
}

While shifts from coral to seaweed dominance have become increasingly common on coral reefs and factors triggering these shifts successively identified, the primary mechanisms involved in coral-algae interactions remain unclear. Amongst various potential mechanisms, algal exudates can mediate increases in microbial activity, leading to localized hypoxic conditions which may cause coral mortality in the direct vicinity. Most of the processes likely causing such algal exudate induced coral mortality have been quantified (e.g. labile organic matter release, increased microbial metabolism, decreased dissolved oxygen availability), yet little is known about how reduced dissolved oxygen concentrations affect competitive dynamics between seaweeds and corals. The goals of this study were to investigate the effects of different levels of oxygen including hypoxic conditions on a common hermatypic coral Acropora yongei and the common green alga Bryopsis pennata. Specifically, we examined how photosynthetic oxygen production, dark and daylight adapted quantum yield, intensity and anatomical distribution of the coral innate fluorescence, and visual estimates of health varied with differing background oxygen conditions. Our results showed that the algae were significantly more tolerant to extremely low oxygen concentrations $\left(2-4 \mathrm{mg} \mathrm{L}^{-1}\right)$ than corals. Furthermore corals could tolerate reduced oxygen concentrations, but only until a given threshold determined by a combination of exposure time and concentration. Exceeding this threshold led to rapid loss of coral tissue and mortality. This study concludes that hypoxia may indeed play a significant role, or in some cases may even be the main cause, for coral tissue loss during coral-algae interaction processes. 
Effects of reduced dissolved oxygen concentrations on

2

3

4

28 * Corresponding authors:

29 Andreas Haas: ahaas@ucsd.edu

30 Dimitri Deheyn: ddeheyn@ucsd.edu

31

32 Keywords: Oxygen, hypoxia, coral-algae competition, fluorescence, photobiology

\section{benthic algae}

\author{
Andreas F. Haas ${ }^{1,2^{*}}$, Jennifer E. Smith ${ }^{2}$, Melissa Thompson ${ }^{2}$, Dimitri D. Deheyn ${ }^{2 *}$
}

${ }^{1}$ Department of Biology, San Diego State University

${ }^{2}$ Scripps Institution of Oceanography, University of California, San Diego 


\section{Abstract}

35 While shifts from coral to seaweed dominance have become increasingly common on coral reefs and factors triggering these shifts successively identified, the primary mechanisms involved in coral-algae interactions remain unclear. Amongst various potential mechanisms, algal exudates can mediate increases in microbial activity, leading to localized hypoxic conditions which may cause coral mortality in the direct vicinity. Most of the processes likely causing such algal exudate induced coral mortality have been quantified (e.g. labile organic matter release, increased microbial metabolism, decreased dissolved oxygen availability), yet little is known about how reduced dissolved oxygen concentrations affect competitive dynamics between seaweeds and corals. The goals of this study were to investigate the effects of different levels of oxygen including hypoxic conditions on a common hermatypic coral Acropora yongei and the common green alga Bryopsis pennata. Specifically, we examined how photosynthetic oxygen production, dark and daylight adapted quantum yield, intensity and anatomical distribution of the coral innate fluorescence, and visual estimates of health varied with differing background oxygen conditions. Our results showed that the algae were significantly more tolerant to extremely low oxygen concentrations $\left(2-4 \mathrm{mg} \mathrm{L}^{-1}\right)$ than corals. Furthermore corals could tolerate reduced oxygen concentrations, but only until a given threshold determined by a combination of exposure time and concentration. Exceeding this threshold led to rapid loss of coral tissue and mortality. This study concludes that hypoxia may indeed play a significant role, or in some cases may even be

53 the main cause, for coral tissue loss during coral-algae interaction processes. 
62

63

64

65

66

67

68

69

70

71

72

73

74

75

76

77

78

79

80

81

82

83

84

85

86

87

88

89

90

91

92

93

\section{Introduction}

Over the last several decades coral cover has been declining around the globe (Gardner et al. 2004; Bruno and Selig 2007). These losses in live coral cover are often associated with increases in the abundance of fleshy algae (Hughes 1994, McCook 1999). Multiple causes for these so called "phase shifts" have been identified including warming and subsequent coral bleaching and mortality or local anthropogenic influences such as pollution and overfishing (Bellwood et al. 2004; McManus and Polsenberg 2004, Hughes et al. 2010). The underlying competitive mechanisms of coral-algae interactions still remain poorly understood (McCook 2001, Jompa and McCook 2003, Smith et al. 2006). However, the outcomes of these competitive interaction processes are critical for determining the resulting relative abundance of these organisms in coral reef habitats (McCook 2001).

Both corals and algae use various physical mechanisms (e.g. sweeper tentacles, messentarial filaments, abrasion, shading) to compete with one another for the limited substratum available on the benthos (Nugues and Roberts 2003, Veghel et al. 1996, Coyer et al. 1993, Tanner 1995). In addition, such competition may also involve direct chemical mechanisms, such as allelopathy (Bak and Borsboom 1984), or the enhancement of disease transfer (Nugues et al. 2004) to other sessile organisms (McCook et al. 2001). Furthermore, an indirect mechanism has also been suggested where organic carbon released by algae promotes microbial activity, which in turn can affect coral physiology and causes damage to the holobiont. The main driver of coral mortality in this proposed scenario is hypoxia resulting from intensified microbial activity and respiration at the coral/algal interface (Smith et al. 2006). There is increasing evidence that algal exudates can cause microbe-mediated coral mortality but more information is needed about the specific mechanisms involved (Barott et al. 2009).

It is known that oxygen concentrations well below saturation level can occur on coral reefs (Nilsson and Östlund-Nilsson 2004, Wild et al. 2010). In such complex environments, in situ oxygen levels can fluctuate widely on a diurnal cycle and can be very low at night when organismal respiration dominates the landscape (Haas et al. 2010a, Wild et al. 2010). The extent of this diurnal fluctuation is thereby largely influenced by the biological nature of the local benthic community (Niggl et al. 2010). For example, dissolved oxygen (DO) concentrations in water surrounding algae-dominated areas can be lower than in adjacent coral-dominated reef areas, reaching DO concentrations as low as $4 \mathrm{mg} \mathrm{L}^{-1}$ (Haas et al. 2010a).

93 Benthic algae are known to release a significant portion of their daily fixed carbon as 
94 photosynthetates, primarily carbohydrates (Haas et al. 2010b), thus enriching the immediate

95 surrounding water with dissolved organic carbon (DOC) (Khailov and Burlakova 1969; Brilinsky

96 1977, Haas et al. 2010a, c). It is also known that water column microbial communities consume

97 some of this DOC. As a result of this carbon uptake (Nelson et al. 2011, Haas et al. 2011)

98 increased microbial metabolism and concomitant consumption of oxygen via respiration (Wild et

99 al. 2010, Haas et al. 2010a), can result in locally confined (from the $\mathrm{mm}$ to $\mathrm{cm}$ spatial scale) but

100 sometimes severe hypoxic conditions (Barott et al. 2009). These hypoxic conditions are likely

101 most severe at night when all taxa are consuming oxygen via respiration but recent studies have

102 shown that increased biological oxygen demand may even outweigh photosynthetic oxygen

103 release during daylight (Haas et al. 2013). Clearly the characteristics of coral algal interaction

104 zones will depend upon the taxa present (their species and relative abundance) and their

105 respective metabolic rates. Despite this variability, controlled laboratory experiments have shown

106 that these hypoxic conditions can be reversed with the addition of antibiotics suggesting that

107 bacteria play a key role in these interactions (Smith et al. 2006).

108 There is thus strong evidence that hypoxia plays an important role in coral-algae 109 competition and therefore on processes structuring coral reef communities (McCook 2001).

110 However, much less is known about how corals and algae individually respond to reduced

111 oxygen conditions. Assuming that algal exudates can fuel microbial community metabolism,

112 resulting in hypoxic conditions at the coral - algal interface, algae need to be more tolerant to

113 these hypoxic conditions than corals to be the competitive superior. The goals of the present

114 study were to investigate the differential tolerance and responses of a common Indo-Pacific coral

115 and a green macroalga to reduced DO conditions in independent incubation experiments.

\section{Material and Methods}

118 This study was conducted in controlled laboratory conditions at the Scripps Institution of

119 Oceanography (SIO) in San Diego, California from July 17 to 27, 2011. The hermatypic coral

120 Acropora yongei initially provided by the Birch Aquarium at Scripps in 2010 has been

121 maintained in culture under optimal growing conditions at Marine Biology Research Division

122 Experimental Aquarium Facility at SIO (Roth et al. 2010). The Birch Aquarium at Scripps also

123 supplied specimens of the green alga Bryopsis pennata specifically for this study. All samples

124 were grown in controlled environments, allowing for better comparison amongst treatments,

125 which is somewhat simplified and possibly not thoroughly reflecting variation and adaptation

126 likely found in-situ. Organisms were kept in identical flow-through tanks with filtered (nominal 
127 pore size $50 \mu \mathrm{m}$ ) and temperature controlled seawater at least 10 days prior to the experiment

128 (from now on referred to as "seawater"). Seawater temperature was monitored at 5 min intervals 129 with data loggers (Onset $\mathrm{HOBO}^{\circledR}$ Pendant UA-002-64) and was $26.3 \pm 0.4{ }^{\circ} \mathrm{C}$ for the duration of 130 the experiment.

131 Adequate irradiance was provided to the corals and algae by artificial illumination $(2 \times 54$

132 W 6000K Aquablue ${ }^{+}, 1$ x 54 W 6000K Midday, and 1 x 54 W Actinic ${ }^{+}$, Geismann, Germany) 133 placed $80 \mathrm{~cm}$ above the surface water level with a day light cycle of 12-12 hrs. The resulting 134 photosynthetically active radiation (PAR) was $120 \mu \mathrm{mol}$ quanta $\mathrm{m}^{-2} \mathrm{~s}^{-1}$, as measured with a 135 LICOR LI-193 Spherical Quantum Sensor.

\section{Sample preparation}

Corals were carefully fragmented into individual branches $(\sim 5 \mathrm{~cm}$ in length) with bone cutters. The coral fragments were then attached to ceramic tiles $(3.6 \times 3.6 \times 1.4 \mathrm{~cm})$ with coral cement (HoldFast ${ }^{\circledR}$, Instant Ocean). A polyethylene holding stick was also attached to the ceramic tile to reduce direct mechanical stress on the organisms during experimental handling, all following a process routinely done in our laboratory (Roth et al. 2010).

Algal specimens were attached to identical tiles using small plastic zip ties. Sizes of all specimens were chosen in a way that both organism groups would have comparable oxygen consumption rates of $\sim 2 \mathrm{mg} \mathrm{L}^{-1}$ during the $12 \mathrm{~h}$ dark incubation period (as determined in preliminary analysis; data not shown). All specimens were allowed to recover from fragmentation for 4 or 2 weeks for corals and algae, respectively.

\section{Experimental set up}

During each $12 \mathrm{~h}$ daytime phase all specimens $(\mathrm{n}=18$ corals, $\mathrm{n}=18$ algae) were kept in their tanks under identical conditions. At the beginning of nighttime, specimens were each

152 incubated in separate airtight containers ( $1 \mathrm{~L}$ mason jars) and subjected to 3 different ( $\mathrm{n}=6$ for 153 each organism group) dark oxygen concentration treatments: $6-8 \mathrm{mg} \mathrm{L}^{-1}$ (ambient oxygen 154 concentrations), $4-6 \mathrm{mg} \mathrm{L}^{-1}$ (decreased oxygen concentration), and $2-4 \mathrm{mg} \mathrm{L}^{-1}$ (low oxygen 155 concentration). Oxygen concentrations were chosen to reflect oxygen concentrations in well 156 mixed, more exposed reef environments (our "ambient" equivalent), more sheltered backreef or 157 low water flow reef environments (our "decreased" equivalent) and oxygen concentrations found 158 at coral-algae interfaces or coral interstices (our "low" equivalent). Reduced dissolved oxygen 159 concentrations were generated by sparging seawater with nitrogen to varying levels prior to the 
160 start of the nighttime experimental treatment, while simultaneously measuring dissolved oxygen

161 concentrations with optical oxygen probes (HACH LANGE HQ40; precision $0.01 \mathrm{mg} \mathrm{L}^{-1}$, 162 accuracy $\pm 0.05 \%$ ) to reach the desired oxygen concentration.

163 The airtight experimental containers were equipped with stir-bars to ensure constant water 164 circulation and were kept in the dark in a temperature-controlled environment $\left(25.9 \pm 0.7^{\circ} \mathrm{C}\right)$ for

$16512 \mathrm{~h}$. At the end of the nocturnal oxygen treatments, specimens were removed from their 166 individual containers and again placed in the daytime maintenance tanks with ambient oxygen 167 concentrations. Seawater from experimental nighttime containers was then rapidly analyzed for 168 dissolved oxygen concentrations to ensure comparable oxygen consumption amongst treatments. 169 This procedure was repeated over 10 consecutive diurnal cycles for all 36 specimens, even when 170 showing clear signs of stress (i.e. bleaching and/or tissue loss).

$171 \quad$ Under such an experimental set up, oxygen consumption during the dark incubations was 172 similar between algae and coral specimens and on average $0.141 \pm 0.006 \mathrm{mg} \mathrm{L}^{-1} \mathrm{~h}^{-1}$ and $0.144 \pm$ $1730.006 \mathrm{mg} \mathrm{L}^{-1} \mathrm{~h}^{-1}$ (mean $\pm \mathrm{SE}$ ) in the respective incubation setups. Both coral and algae exposed to

174 low oxygen treatments $\left(2-4 \mathrm{mg} \mathrm{L}^{-1}\right)$ showed significantly higher oxygen consumption rates $(\mathrm{F}=$ $1755.21, \mathrm{p}<0.001)$ compared to the algae in decreased oxygen treatments $\left(4-6 \mathrm{mg} \mathrm{L}^{-1}\right)$ or ambient 176 oxygen concentration treatments $\left(6-8 \mathrm{mg} \mathrm{L}^{-1}\right)$ (Table 1$)$.

\section{Biological parameters measured}

179 Overall health of corals and algae was assessed separately using a combination of measurements 180 on each sample. Photosynthetic oxygen production assessments and PAM measurements were 181 used to address changes in the photosynthetic performance of the specimens and photographic 182 analysis was used to assess the general health of coral and the growth rates of the algae (detailed 183 description below). All described measurements were conducted on day $-3,0,1,3,7$, and 10 of 184 the experiment.

186 Changes in oxygen production during photosynthesis were assessed by placing each specimen in 187 an individual, temperature-controlled and gently stirred $(\sim 90 \mathrm{rpm})$ beaker during daylight hours 188 (between 1000-1230 PST). Initial DO readings were obtained from each beaker using the above 189 mentioned oxygen optodes. Beakers were then sealed airtight and placed back under artificial 190 daylight conditions; a final DO reading was taken after $150 \mathrm{~min}$. The difference between the 191 initial and final DO readings was used as the net photosynthetic oxygen production rate of each 192 specimen. After these measurements the organisms were then placed back in their respective 
maintenance tanks.

Pulsed Amplitude Modulation (PAM) fluorescence was used to assess the photosynthetic efficiency of the organisms (Ralph et al. 1998). The photochemical efficiency of PSII was evaluated by measuring the quantum yield (QY) derived from the $F \mathrm{v} / F \mathrm{~m}$ values obtained from

198 the PAM, where $F \mathrm{~V}$ is variable fluorescence and $F \mathrm{~m}$ is maximum fluorescence of the measurements. PSII fluorescence measurements were conducted following saturating light pulses (800 ms flashes of 8,000 $\mu \mathrm{mol}$ quanta $\mathrm{m}^{-2} \mathrm{~s}^{-1} \mathrm{PAR}$ ). In this study we assessed dark-adapted (or maximum) QY during early pre-dawn hours (analyses from 07:00 to 08:00 PST) and daylight adapted (or effective) QY during mid-day (analyses from 14:00 to 15:00 PST), after $6 \mathrm{~h}$ of full light exposure (Genty et al. 1989).

Digital image analysis was systematically performed under identical conditions for all samples throughout the experimental period. Green fluorescence was hereby used as a general indicator for coral health, while red fluorescence was used as estimation for functional chlorophyll abundance. Images from corals and algae submerged in seawater were collected using a Nikon SMZ 1500 microscope equipped with an epi-fluorescence setup and X-cite 120 (EXFO, Lumen Dynamic) mercury lamp for excitation light source (see Roth et al. 2010 for details). A RETIGA 2000R QImaging (photometrics) digital camera was used to take the pictures through computer controlled Q-Capture Pro software. For each day of analysis, calibration images of a white ruler with fluorescence in the green were taken with identical settings in order to allow for detection of

214 potential drift from the instrumentation. All images (tiff) of organisms were then analyzed in Matlab 7.5 (Mathworks Inc., Natick, MA, USA) as described in Roth et al. (2010).

Specimens were photographed under full light spectrum of a Dolan-Jenner 180 Fiberthat data for the fluorescence at day 0 for one coral was lost, resulting in lower replication for some of the analyses based on changes from day 0 to 10 . For the coral, white light images were used to calculate the ratio of pixels showing white color ( $90 \%$ saturation) versus the entire number of pixels. White light images were used to calculate surface area of the specimens. The surface area was then used to calculate the specimen's average green fluorescence intensity by subtracting the average background pixel intensity from the green pixel intensity, which was then

224 summed and divided by the surface area. White light images were also used for a qualitative 225 visual evaluation of coral and algae health, with special attention on changes in size, color, 
226 lesions, and/or loss of tissue. The flexible and overlapping nature of the algal specimens did not

227 allow for precise quantification; yet images were used to estimate relative algal growth by

228 quantifying the red fraction of pixels (in fluorescence, thus representing chlorophyll) from each

229 of the respective images over the duration of the experiment.

231 Statistical analysis

232 All data (oxygen production, Maximum QY, Effective QY, Red fluorescence fraction, Green 233 fluorescence intensity, Green fluorescence fraction) were log-transformed data to meet 234 assumptions of normality and homocedasticity. Effects of different oxygen treatments on the 235 coral and algal samples were tested for significance by comparing changes in a variety of 236 parameters from experimental day 0 to 10 only. The comparison tested the difference in the 237 magnitude of change from start to end of the experimental period for a given treatment using one238 way analysis of variance (ANOVA), and differences among oxygen treatments were assessed 239 with Tukey post hoc tests $(\alpha=0.05)$. For all measurements conducted on both coral and algae a 240 two-way ANOVA with oxygen treatment (3-levels) and species (2-levels) was used (which thus 241 excludes the fluorescence analyses that were different for each species). Comparisons between 242 light and dark-adapted QY measurements conducted for each specimen were performed using a 243 paired sample T-test. Results showing the main effects and the interactions are given in Table S1. 244 These statistical evaluations were performed using SAS within the software package JMP (v9; 245 SAS institute 1989-2011).

246 Additionally a Repeated-Measures-ANOVA was used to incorporate in the analysis the 247 percent of change found in the data that relates to the evolution over time of individual coral and 248 algal samples repeatedly measured during their exposure to different treatment conditions. The 249 factors in this analysis include the experimental oxygen treatment, the time point, the repetition 250 of measurements from the same samples (Individual factor) and its variation over time 251 (Repetition $\mathrm{x}$ Time factor). The percent of variance explained by each factor (or combination of 252 factors) on the measurements made from the corals and alga was based on the relative expression 253 of the Sum of Squares of each factor to the total of the Sum of Squares. The percent of variance 254 remaining unexplained was listed as a residual factor and analyses were conducted with the 255 statistical software Statview ${ }^{\circledR} 5.0$ (SAS Institute, Inc.).

\section{Results}


Overall, the different oxygen treatments significantly affected various metrics of coral

259 health while no significant impacts were found on algal health and/or physiology. This was clear

260 in particular for the fluorescence analyses that were, however, specific to each organism (see 261 specific sections below). When considering the analysis common to both the coral and the algae,

262 the effects of oxygen depletion treatment were greater for the maximum quantum yield, while the 263 effective quantum yield and the photosynthetic oxygen production were less affected (Table S1). 264 Maximum quantum yield appeared affected significantly by the oxygen treatment and species, as 265 well as their interaction; thus the oxygen depletion had effects that were different between coral and algae with regards to the maximum quantum yield (species*oxygen treatment of Max. QY; Table S1). As for the effective quantum yield, it showed significant difference between organisms, but in both species this parameter showed no significant variation with the oxygen treatment (whether oxygen treatment or species*oxygen treatment; Table S1). As for the photosynthetic oxygen production, it was not significantly different between organisms, yet was a parameter sensitive to oxygen treatment especially when considering it within species (species*oxygen treatment; Table S1).

Photosynthetic oxygen production measurements were not different over the course of the experiment for all algae treatments and for corals in the ambient $\left(6-8 \mathrm{mg} \mathrm{L}^{-1}\right)$ and decreased $(4$ $\left.-6 \mathrm{mg} \mathrm{L} \mathrm{L}^{-1}\right)$ oxygen treatment. Corals in the low oxygen treatment $\left(2-4 \mathrm{mg} \mathrm{L}^{-1}\right)$ showed a significant decline in oxygen production rates $(52.7 \pm 12.7 \%$ of the initial values) over the experimental period (Fig. 1.1, Table 2). All algae displayed an initial tendency to decrease on the first experimental day but recovered from day one onward, and reached their initial levels again by the end of the experimental period (Fig. 1.1A).

PAM measurements. Over the course of the 10-day experiment dark-adapted QY values recovered for all specimens to pre-experimental values, except for corals subjected to the low oxygen treatment. In this treatment the dark-adapted QY values gradually declined until they reached $\sim 70 \%$ of their initial values on day three and stayed at this level thereafter (Fig. 1.2 BE). Decreases in dark-adapted QY values of corals subjected to low oxygen treatment were significantly greater at the end of the experiment than of any other coral treatment (Tukey $\mathrm{p}<$ 0.05) Fig. 1.2 E, Table 2).

Daylight adapted QY measurements followed the same pattern as the dark-adapted QY 288 (data not shown). After a slight initial decrease, daylight adapted QY recovered in all treatments 289 to pre-experimental conditions, except in the low oxygen coral treatment, which stayed at $\sim 80 \%$ 290 of the initial value. This treatment showed significantly greater decreases than all other 
treatments.

292 Daylight and dark-adapted QY values were always in the same range and, with one exception, dark-adapted QY values were always higher for the same specimen on the same day as daylight adapted QY. Only on day 10 in the $2-4 \mathrm{mg} \mathrm{L}^{-1}$ oxygen treatment all coral specimens

295 showed significantly higher daylight adapted QY than the dark-adapted QY values (paired sample T-test; $\mathrm{p}=0.038$; Fig. S1).

Fluorescence analysis of algae showed significantly higher fraction of red pixels at the end of the experiment for all treatments $(\mathrm{F}=27.46, \mathrm{p}<0.001)$, yet with no detectable difference in the rate of increase between the respective oxygen treatments (Fig. 1.3). Although there was an initial drop in the fraction of red pixels, which was similar with all parameters measured for algae (Fig. 1.3 A - C), a strong increase in the fraction of red pixels in algae samples from day 3 onward suggests a constant growth or increase in chlorophyll concentration for these specimens (Fig $1.3 \mathrm{~A}, \mathrm{D}, \mathrm{E})$

Coral fluorescence analysis revealed significant decreases in green intensity between the 2-4 and 4-6 mg L ${ }^{-1}$ treatments compared to the $6-8 \mathrm{mg} \mathrm{L}^{-1}$ control treatment at the end of the experiment $\left(\mathrm{F}_{(2,14)}=4.60, \mathrm{p}=0.029\right)$ (Fig. $1.4 \mathrm{E}$, Table 2). Green fluorescence intensity values for the $6-8 \mathrm{mg} \mathrm{L}^{-1}$ control treatment stayed in the same range throughout the experiment (Fig. 1.4 A). The fluorescence intensities in the $4-6 \mathrm{mg} \mathrm{L}^{-1}$ treatment gradually declined over the course of the experiment, while in the $2-4 \mathrm{mg} \mathrm{L}^{-1}$ treatment they decreased rapidly to the point of not being detectable after day 3 (Fig. $1.4 \mathrm{~A}-\mathrm{E}$ ). Because intensity measurements were calculated for each individual pixel on the green channel, we also determined whether the number of pixels in the green channel changed, representing the area of fluorescence in the samples. While the area

313 of green fluorescence remained similar for corals in the $6-8 \mathrm{mg} \mathrm{L}^{-1}$ control treatment over the 314 duration of the experiment, there was a gradual decrease in the $4-6 \mathrm{mg} \mathrm{L}^{-1}$ treatment; the area of 315 green fluorescence was about $3 \times$ smaller than the control by the end of the experiment (Fig 1.5 $316 \mathrm{~A}, \mathrm{C}-\mathrm{E})$. The fraction of green pixels in corals showed significantly greater decreases in the 2 -

$3174 \mathrm{mg} \mathrm{L}^{-1}$ oxygen treatment than in the $4-6$ and $6-8 \mathrm{mg} \mathrm{L}^{-1}$ treatments by the end of the 318 experiment $\left(\mathrm{F}_{(2,15)}=63.21, \mathrm{p}<0.001\right)$, being about $10 \mathrm{x}$ smaller than in the controls (Fig. $1.5 \mathrm{~A}-$ 319 E). The fraction of green fluorescent pixels rapidly declined within the first three experimental 320 days (Fig 1.5 A) and was barely detectable by the end of the experiment.

The intensity of fluorescence and the amount of pixels producing green fluorescence are

322 inherently correlated and they were thus multiplied in order to obtain one single combined "green 323 fluorescence parameter" (Fig. S2). This parameter was significantly different amongst corals 
324 from all three oxygen treatments at the end of the experiment (Table 2).

325 In contrast, the increase in the signal of coral red fluorescence in the $2-4 \mathrm{mg} \mathrm{L}^{-1}$ (Fig 1.6

$326 \mathrm{~A}-\mathrm{C}$ ) was significantly higher than in the $6-8 \mathrm{mg} \mathrm{L}^{-1}$ control treatment at the end of the

327 experiment (Table 2). The $4-6 \mathrm{mg} \mathrm{L}^{-1}$ treatment showed slight increases in the intensity of red

328 pixels over the experimental period, but values were not significantly different from those of

329 either of the other treatments at the end of the experiment (Fig. 1.6 D, E; Table 2).

330 Visual census indicated that all corals subjected to low $\left(2-4 \mathrm{mg} \mathrm{L}^{-1}\right)$ oxygen treatments

331 had lesions and partial tissue loss within the first 3 days and all specimens were dead or dying,

332 with no coral tissue covering the calcareous coral skeleton, after day 3 (Fig. 3). These specimens

333 rapidly became discolored (in bright field) instead of staying white, likely the result of a

334 microbial film and/or endolithic or micro-algae growing in/on the skeleton. No other

335 experimental specimens, under any of the other treatments showed visually detectable signs of

336 stress or tissue loss during the course of the experiment.

Repeated-measures-ANOVA showed that algae and corals had distinct responses to the various oxygen treatments, but also that these responses were primarily driven by different factors (Table S2). The algae showed little response to the oxygen treatments (responsible for 0.6 $\%$ of changes in red fluorescence, and up to $12.5 \%$ for $\mathrm{O}_{2}$ production). The majority of effects observed in algae were driven by the Time factor (ranging from $14.4 \%$ for the Effective QY to

$34347.5 \%$ for the Maximum QY) and the Residual factor (ranging from $31.1 \%$ for the maximum 344 QY to $50.5 \%$ for the Effective QY) (Table S2).

The influence of these factors was differently distributed for corals. The Treatment factor contributed from $14.1 \%$ (for daylight oxygen production rates) to $41.0 \%$ (for green fluorescence

347 fraction) of the observed variability and was always (except for $\mathrm{O}_{2}$ production) a statistically 348 significant factor (Maximum QY: $F=9.998, \mathrm{p}=0.0017$; Effective QY: $\mathrm{F}=8.386, \mathrm{p}=0.0036$; Green fluorescence intensity: $F=8.699, p=0.0035$; Green fluorescence fraction: $F=33.453, p<$ 0.0001; Green fluorescence intensity * fraction: $\mathrm{F}=21.752, \mathrm{p}<0.0001$; Red fluorescence intensity: $\mathrm{F}=17.223, \mathrm{p}=0.0001)$. The Time factor contributed less to the variability but was still

352 important, with contribution ranging from $9.2 \%$ (for green fluorescence fraction) to $37.6 \%$ (for 353 daylight oxygen production rates). These results indicate that for the corals, daytime oxygen 354 production rates were the least affected parameter after repeated exposure to nighttime hypoxia, 355 while the fraction of green fluorescence was the most affected. Repetition factor effects ranged 356 from $1.5 \%$ for $\mathrm{O}_{2}$ production to $15.6 \%$ for the Maximum QY, and from $15.6 \%$ for the red 
357 fluorescence fraction to $39.3 \%$ for the Green fluorescence fraction. Such a large effect was also 358 observed for the red fluorescence of algae (37.7\%) thus suggesting that measuring fluorescence 359 from complex-shaped samples (such as organisms) as a strong inherent variability due to 360 repetition that needs to be taken into account. This variability also evolved with time since the 361 Repetition * Time factor was often significant, ranging from $10.7 \%$ for the Green Fluorescence 362 intensity to $22.4 \%$ for the Green Fluorescence fraction, while ranging from $9.3 \%$ for oxygen 363 production to $23.3 \%$ for Effective QY. As for the Residual factor, it was usually lower in corals 364 than for algae, ranging from $4.6 \%$ for the Green Fluorescence fraction to $37.5 \%$ for the $\mathrm{O}_{2}$ 365 production (Table S2).

\section{Discussion}

Here we examined the response of a common species of coral and reef algae to experimentally manipulated oxygen conditions reported to occur at night in coral reef environments, where DO can decrease dramatically in certain areas, due to organismal respiration and microbial metabolism. Hypoxia, defined as dissolved oxygen concentrations below $2 \mathrm{mg} \mathrm{L}^{-1}$ (Stevenson and Wyman 1991) has been repeatedly described in coral reef ecosystems, especially within interaction zones or reef interstices (Shashar et al. 1993, Barott et al. 2009). Hypoxia has also been hypothesized to play a role in coral mortality at the location of coral algal interaction zones (Smith et al. 2006, Barott et al. 2009). This study demonstrates for the first time that low oxygen concentrations can have deleterious effects on the health and physiology of a hermatypic coral, Acropora yongei, while causing little to no effect on the common green alga Bryopsis pennata.

\section{Physiological effects of decreased oxygen concentrations}

While the alga showed no measurable response to exposure to the different oxygen, the hermatypic coral A. yongei displayed significant alterations in all parameters measured, when subjected to the low oxygen $\left(2-4 \mathrm{mg} \mathrm{L}^{-1}\right)$ treatment. The samples in these treatments, without exception, appeared bleached, lost major portions of their tissue and most likely were deceased within 3 days of the experiment. The visible decline in coral health was accompanied by a significant decrease in photosynthetic performance, which was assessed via oxygen production rates, dark-adapted maximum quantum yield, and daylight adapted effective quantum yield measurements. Surprisingly, photosynthetic activity of these low oxygen treatment coral specimens was still measurable on experimental day 3 and remained at a constant level of $50-80$ 
$390 \%$ of the initial measurements thereafter. This could either have been related to remaining 391 zooxanthellae (though unlikely), endolithic algae, and/or colonization of the bare coral skeleton 392 by cyanobacteria or microalgae. The latter is supported by the observation of tissue loss and, 393 subsequently, a greenish coloration that the bleached coral skeleton rapidly acquired. The 394 photosynthetic organisms associated with the low oxygen coral samples at the end of the 395 experiment showed higher values of effective than maximum QY. This exception might stem 396 from a fast regeneration of their photosystems after the cessation of the nocturnal hypoxic stress 397 conditions, which potentially compromised the photosynthetic performance of these organisms.

398 The visual census showed that the coral tissue in low oxygen treatments dissolved within 399 the initial 3 days. This clearly attributes all photosynthetic performance measured after day 3 to 400 endolithic algae and/or microalgae rapidly colonizing the coral skeleton. It further indicates that 401 the bare coral skeletons were immediately colonized by microalgae, capitalizing on the new hard 402 substratum, even though parts of the colony were still covered with residual coral tissue on 403 experimental day $1-3$. 


\section{Green fluorescence}

406 Physiological measurements were supported by results obtained from analysis of

407 fluorescence images. The scleractinian coral A. yongei used in this experiment produces proteins 408 that fluoresce exclusively in green (GFPs) (Roth et al. 2010, 2012). GFPs are ubiquitous in 409 scleractinian corals (Alieva et al. 2008; Gruber et al. 2008; Salih et al. 2000) and can constitute a 410 significant portion of their total protein content (Leutenegger et al. 2007). Although there is 411 currently no consensus on the physiological function/s of these proteins in corals, previous 412 studies have demonstrated the potential to use GFPs as an indicator of health of the organism 413 (Roth and Deheyn 2013). Here the green fluorescence was significantly affected in the corals 414 subjected to the low oxygen treatments. There were also significant responses detectable by 415 fluorescence analysis for coral specimens subjected to $4-6 \mathrm{mg} \mathrm{L}^{-1}$ nighttime oxygen 416 concentrations. Noticeable decreases in the intensity of green pixels were accompanied by a 417 slight decrease in the extent of the fluorescent area (thus decrease in number of green pixels). We 418 combined the GFP responses to the different treatments by multiplying the green fluorescence 419 intensity (intensity of pixels with fluorescence) by the fraction of the green signal (number of 420 pixels with fluorescence) in each picture (i.e. intensity * abundance). The combination of both 421 parameters incorporates changes of the fluorescence intensity from the proteins themselves as 422 well as the difference in spatial distribution of the fluorescence (coenosarc and polyps versus 423 mainly polyps). This spatial difference of the green fluorescence that becomes mainly visible 424 around the polyps can be interpreted as the result of (1) the green fluorescence is increasingly 425 shaded by the increasing amount of zooxanthellae, especially in the coenosarc (see following 426 section), and/or (2) the GFP could be denatured following some biochemical reaction such as 427 free-radical chelation, (Bou-Abdallah et al. 2006; Palmer et al. 2009) which could be more 428 pronounced in the coenosarcs (Fig. S1). The clear detection of subtle changes in corals subjected 429 to the decreased oxygen treatment suggests that coral fluorescence may be an extremely sensitive 430 indicator to assess overall coral health (Roth et al. 2010, 2012, Roth and Deheyn 2013) and 431 further emphasizes the value and sensibility of fluorescence analytical methods in determining 432 early stage changes in coral health conditions (see also Table S1).

\section{Red fluorescence}

435 Fluorescence signals can also be used to distinguish between pigmented and bleached 436 corals and between coral and algae (Myers et al. 1999). Emission in red, at wavelengths longer 437 than $630 \mathrm{~nm}$, is not generated by the coral host (Mazel 1995, Salih et al. 2000., Neori et al. 1988), 
438 but from photosynthetic pigments found in their algal symbionts (Jeffrey and Haxo 1968), which

439 show a distinct chlorophyll peak at $680 \mathrm{~nm}$ (red light) when excited with blue light (480 nm)

440 (Gurskaya et al. 2001). The detected rise in red fluorescence for corals in low oxygen treatments

441 may therefore either be attributed to increases in zooxanthellae (yet unlikely since the corals were

442 bleached and dying), or to the growth of endolithic algae (already present in the coral skeleton),

443 cyanobacteria and/or filamentous algae starting to colonize the bare coral skeleton (Shashar et al.

444 1997; Zawada and Jaffe 2003).

445 While green fluorescence was more visible in the polyp tissue, red fluorescence, initially

446 generated by the endosymbiotic zooxanthellae, was mainly visible in the coenosarcs of the coral

447 fragments. This particular compartmentalization is not a general feature for the species A. yongei

448 (Roth et al. 2010) as the difference in anatomic distribution of coral pigments and associated

449 zooxanthellae can be dynamic and vary within and between coral species (Gruber et al. 2008;

450 Oswald et al. 2007). However, the strong decrease and eventual extinction of green fluorescence

451 (when compared to background values), which was paralleled by a uniform increase in red

452 fluorescence of corals subjected to low oxygen concentrations, suggests the growth of endolithic

453 and/or opportunistic filamentous algae in/on the coral skeleton rather than an increase in 454 symbiontic zooxanthellae.

455 In contrast to the corals, the area of red fluorescence generated by the photosynthetic 456 pigments of the alga Bryopsis p. increased gradually over time in all treatments, indicating 457 similar growth of all algae samples regardless of the nighttime oxygen concentration treatments.

\section{Conclusion}

Although extremely low oxygen concentrations $\left(2-4 \mathrm{mg} \mathrm{L}^{-1}\right)$ had severe impacts on $A$. yongei specimens over a short period of time (Fig.1; Table S1), we also show that corals were able to tolerate reduced oxygen concentrations reasibably well (within $4-6 \mathrm{mg} \mathrm{L}^{-1}$ ). Nighttime oxygen concentrations between 4 and $6 \mathrm{mg} \mathrm{L}^{-1}$, which are commonly found during the early morning hours in various reef locations (Kraines et al. 1996, Niggl et al. 2010, Wild et al. 2010, Haas et al. 2010a), showed some effects on fluorescent proteins, but not on the physiological performance of the respective corals over the experimental period of 10 days. A surplus of oxygen consumption to naturally occurring low nighttime DO concentrations, as may be facilitated by proximate algae in combination with algal exudate induced increases in microbial oxygen consumption, may however exceed the tolerance $\left(<4 \mathrm{mg} \mathrm{L}^{-1}\right)$ and lead to rapid tissue loss and colonization of the calcareous coral structure by algae (Fig. 3). Additional evidence on the 
471 importance of this interaction mechanism is given by studies conducted by Barott et al. (2009),

472 who showed that oxygen concentrations on the interfaces of coral algae interaction zones were on 473 average $3.2 \pm 0.5$ and $2.9 \pm 0.4 \mathrm{mg} \mathrm{L}^{-1}$ when algae were the superior competitors (Pocillopora 474 verrucosa vs. mixed red turf algae and Montipora sp. vs. mixed red turf algae, respectively); an 475 oxygen concentration which is just below the coral tolerance threshold suggested by the present 476 study, but not harmful to the algae we studied. The study further revealed that for coral algae 477 interaction zones, where both organisms were in a stable state or corals were the superior 478 competitor (Favia sp., Montipora sp. and Pocillopora sp. vs. crustose coralline algae), oxygen 479 concentrations on the interfaces were on average $7.9 \pm 0.7 \mathrm{mg} \mathrm{L}^{-1}$, i.e. well above the suggested 480 threshold of $4 \mathrm{mg} \mathrm{L}^{-1}$.

481 Finally, our study presents two main findings: (1) the alga Bryopsis pennata was 482 significantly more tolerant than the hermatypic coral Acropora yongei toextremely low oxygen 483 concentrations $\left(<4 \mathrm{mg} \mathrm{L}^{-1}\right)$, and (2) the coral could tolerate decreased oxygen concentrations up 484 to a given point. The threshold $\left(\sim 4 \mathrm{mg} \mathrm{L}^{-1}\right)$ is below reported diurnal oscillations facilitated by 485 the coral reef community metabolism, but lies within oxygen concentrations reported from the 486 interface along coral algae interaction zones. Beyond this threshold the corals used in this study 487 experienced rapid loss of tissue and death of the whole organism. This study therefore suggests 488 that hypoxia may be a factor influencing competitive interactions between the reef-building 489 corals such as $A$. yongei and common benthic algae such as B. pennata. Further research will 490 investigate whether such mechanisms could be generalized to other species of corals and algae.

\section{Acknowledgements.}

493 This research was supported by the United States National Science Foundation (NSF) award 494 OCE-0927448 to Jennifer E. Smith, and by the Air Force Office of Scientific Research (AFOSR) 495 Natural Materials and System and Extremophiles Program, under award FA9550-10-1-0112 to 496 Dimitri Deheyn. 


\section{References}

\section{8}

499

500

501

502

503

504

505

506

507

508

509

510

511

512

513

514

515

516

517

518

519

520

521

522

523

524

525

526

527

528

529

530

531

532

533

534

535

536

537

538

539

540

541

542

543

544

545

546

547

548

549

550

551

552

553
Alieva NO, Konzen KA, Field SF, Meleshkevitch EA, Hunt ME, Beltran-Ramirez V, Miller DJ, Wiedenmann J, Salih A, Matz MV. 2008. Diversity and evolution of coral fluorescent proteins. PLoS ONE 3: e2680. doi:10.1371/journal.pone.0002680

Bou-Abdallah F, Chasteen ND, Lesser MP. 2006. Quenching of superoxide radicals by green fluorescent protein. Biochimica and Biophysica Acta 1760:1690-1695.

Bak RPM, Borsboom JLA. 1984. Allelopathic interaction between a reef coelenterate and benthic algae. Oecologia 63:194-198.

Barott K., SmithJE, Dinsdale E, Hatay M, Sandin S, Rohwer F. 2009. Hyperspectral and physiological analyses of coral-algal interactions. PLoS ONE 4: e8043. doi:10.1371/journal.pone.0008043

Bellwood DR, Hughes TP, Folke C, Nyström M. 2004. Confronting the coral reef crisis. Nature 429: 827-833.

Brylinsky M. 1977. Release of dissolved organic matter by some marine macrophytes. Marine Biology 39:213-220.

Done TJ. 1992. Phase shifts in coral reef communities and their ecological significance. Hydrobiologia 247:121-132.

Genty B, Briantais JM, Baker NR. 1989. The relationship between the quantum yield of photosynthetic electron transport and quenching of chlorophyll fluorescence. Biochimica and Biophysica Acta 990:87-92.

Goreau TJ, Cervino J, Goreau M, Hayes R, Hayes M, Richardson L, Smith G, DeMeyer K, Nagelkerken I, GarzonFerrera J, Gil D, Garrison G, Williams EH, Bunkley-Williams L, Quirolo C, Patterson K, Porter JW, Porter K. 1998. Rapid spread of disease in Caribbean coral reefs. Revista de Biologia Tropical 5:157-171.

Gruber DF, Kao HT, Janoschka S, Tsai J, Pieribone VA. 2008. Patterns of fluorescent protein expression in scleractinian corals. The Biological Bulletin 215:143-154.

Gurskaya NG, Fradkov AF, Terskikh A, Matz MV, Labas YA, Martynov VI, Yanushevich YG, Lukyanov KA, Lukyanov SA. 2001. GFP-like chromoproteins as a source of far-red fluorescent proteins. FEBS Letters. 507:16-20.

Haas AF, Jantzen C, Naumann MS, Iglesias-Prieto R, Wild C. 2010a. Organic matter release by the dominant primary producers in a Caribbean reef lagoon: implication for in situ $\mathrm{O}_{2}$ availability. Marine Ecology Progress Series 409:27-39.

Haas AF, Wild C. 2010b. Composition analysis of organic matter released by cosmopolitan coral reef associated green algae. Aquatic Biology 10:131-138.

Haas AF, Naumann MS, Struck U, Mayr C, el-Zibdah M, Wild C. 2010c. Organic matter release by coral reef associated benthic algae in the Northern Red Sea. Journal of Experimental Marine Biology and Ecology 389:53-60.

Haas AF, Nelson CE, Wegley Kelly L, Carlson CA, Rohwer F, Leichter JJ, Wyatt A, Jennifer E. Smith JE. 2011. Effects of coral reef benthic primary producers on dissolved organic carbon and microbial activity. PLoS ONE 6:e27973. doi:10.1371/journal.pone.0027973

Haas AF, Gregg AK, Smith JE, Abieri ML, Hatay M, Rohwer F. 2013. Visualization of oxygen distribution patterns caused by coral and algae. PeerJ 1:e106 http://dx.doi.org/10.7717/peerj.106

Harvell CD, Kim K, Burkholder JM, Colwell RR, Epstein PR,Grimes DJ, Hofmann EE, Lipp EK, Osterhaus ADME, Overstreet RM. 1999. Emerging marine diseases: Climate links and anthropogenic factors. Science 285:15051510 .

Hughes TP. 1994. Catastrophes, phase shifts, and large-scale degradation of a Caribbean coral reef. Science 265: 1547-1551.

Hughes TP, Graham NAJ, Jackson JBC, Mumby PJ, Steneck RS. 2010. Rising to the challenge of sustaining coral reef resilience. Trends in Ecology and Evolution 25:633-642.

Jeffrey SW, Haxo FT. 1968. Photosynthetic pigments of symbiotic dinoflagellates (Zooxanthellae) from corals and clams. The Biological Bulletin 135:149-165.

Jompa J, McCook LJ. 2003. Coral-algal competition: macroalgae with different properties have different effects on corals. Marine Ecology Progress Series 258:87-95.

Khailov KM, Burlakova ZP. 1969. Release of dissolved organic matter by marine seaweeds and distribution of their total organic production to inshore communities. Limnology and Oceanography 14:521-527.

Kraines S, Suzuki Y, Yamada K, Komiyama H. 1996. Separating biological and physical changes in dissolved oxygen concentration in a coral reef. Limnology and Oceanography 41:1790-1799.

Leutenegger A, D'Angelo C, Matz MV, Denzel A, Oswald F, Salih A, Nienhaus GU, Wiedenmann J.

2007. It's cheap to be colorful - Anthozoans show a slow turnover of GFP-like proteins. FEBS Journal 274:24962505.

Mazel CH. 1995. Spectral measurements of fluorescence emission in Caribbean cnidarians. Marine Ecology Progress Series 120:185-191. 
McCook LJ. 1999. Macroalgae, nutrients and phase shifts on coral reefs: scientific issues and management consequences for the Great Barrier Reef. Coral Reefs 18:357-367.

McCook LJ. 2001. Competition between corals and algal turfs along a gradient of terrestrial influence in the nearshore central Great Barrier Reef. Coral Reefs 19:419-425.

McCook LJ, Jompa J, Diaz-Pulido G. 2001. Competition between corals and algae on coral reefs: a review of evidence and mechanisms. Coral Reefs 19:400-417.

McManus JW, Polsenberg JF. 2004. Coral-algal phase shifts on coral reefs: ecological and environmental aspects. Progress in Oceanography 60:263-279.

Myers MR, Hardy JT, Mazel CH, Dustan P. 1999. Optical spectra and pigmentation of Caribbean reef corals and macroalgae. Coral Reefs 18:179-186.

Nelson CE, Alldredge AL, McCliment EA, Amaral-Zettler LA, Carlson CA. 2011. Depleted dissolved organic carbon and distinct bacterial communities in the water column of a rapid-flushing coral reef ecosystem. ISME Journal 5:1374-1387.

Neori A, Vernet M, Holm-Hansen O, Haxo FT. 1988. Comparison of chlorophyll far-red and red fluorescence excitation spectra with photosynthetic oxygen action spectra for photosystem II in algae. Marine Ecology Progress Series 44:297-302.

Niggl W, Haas AF, Wild C. 2010. Benthic community composition affects $\mathrm{O}_{2}$ availability and variability in a Northern Red Sea fringing reef. Hydrobiologia 644:401-405.

Nilsson GE, Östlund-Nilsson S. 2004. Hypoxia in paradise: widespread hypoxia tolerance in coral reef fishes. Series B: Biological Sciences 271:S30-S33.

Nugues MM, Roberts CM. 2003. Coral mortality and competition with algae in relation to sedimentation. Coral Reefs 22:507-516.

Nugues MM, Smith GW, van Hooidonk RJ, Seabra MI, Bak RPM. 2004. Algal contact as a trigger for coral disease. Ecology Letters 7:919-923.

Oswald F, Schmitt F, Leutenegger A, Ivanchenko S, D’Angelo C, Salih A, Maslakova S, Bulina M, Schirmbeck R, Nienhaus GU, Matz MV, Wiedenmann J. 2007. Contributions of host and symbiont pigments to the coloration of reef corals. FEBS Journal 274:1102-1109.

Palmer CV, Modi CK, Mydlarz LD. 2009. Coral fluorescent proteins as antioxidants. PLoSONE 4,e7298

Ralph PJ, Gademen G, Dennison WC. 1998. In situ seagrass photosynthesis measured using a submersible, pulseamplitude modulated fluorometer. Marine Biology 132:367-373.

Rasher DB, Hay ME. 2010. Chemically rich seaweeds poison corals when not controlled by herbivores. Proceedings of the National Acadademy of Science USA 107:9683-9688.

Roth MS, Deheyn DD. 2013. Effects of cold stress and heat stress on coral fluorescence in reef-building corals. Scientific Reports 3:1421.

Roth MS, Latz MI, Goericke R, Deheyn DD. 2010. Green fluorescent protein regulation in the coral Acropora yongei during photoacclimation. Journal of Experimental Biology 213:3644-3655.

Salih A, Larkum A, Cox G, Kühl M, Hoegh-Guldberg O. 2000. Fluorescent pigments in corals are photoprotective. Nature 408:850-853.

Shashar N, Cohen Y, Loya Y. 1993. Extreme diel fluctuations of oxygen in diffusive boundary layers surrounding stony corals. Biological Bulletin 185:455-461.

Shashar N, Banaszak AT, Lesser MP, Amrami D. 1997. Coral endolithic algae: life in a protected environment. Pacific Science 51:167-173.

Smith JE, Smith CM, Hunter CL. 2001. An experimental analysis of the effects of herbivory and nutrient enrichment on benthic dynamics on a Hawaiian reef. Coral Reefs 19:332-342.

Smith JE, Shaw M, Edwards RA, Obura D, Pantos O, Sala E, Sandin SA, Smriga S, Hatay M, Rohwer F. 2006. Indirect effects of algae on coral: algae-mediated, microbe-induced coral mortality. Ecology Letters 9:835845.

Stevenson LH, Wyman B. 1991. Hypoxia. in Dictionary of Environmental Science: New York, p 125

Tanner JE. 1995. Competition between scleractinian corals and macroalgae: an experimental investigation of coral growth, survival and reproduction. Journal of Experimental Marine Biology and Ecology 190:151-168.

Van Veghel MLJ, Cleary DFR, Bak RPM. 1996. Interspecific interactions and competitive ability of the polymorphic reef-building coral Montastrea annularis. Bulletin of Marine Science 58:792-803.

Wild C, Niggl W, Naumann MS, Haas AF. 2010. Organic matter release by Red Sea coral reef organisms - potential effects on microbial activity and in-situ $\mathrm{O}_{2}$ availability. Marine Ecology Progress Series 411:61-71.

Zawada DG, Jaffe JS. 2003. Changes in the fluorescence of the Caribbean coral Montastraea faveolata during heatinduced bleaching. Limnology and Oceanography 48:412-425. 


\section{Tables}

612 Table 1: Oxygen concentrations (mean \pm standard error) measured at start and end of nighttime 613 oxygen treatments along with the corresponding nighttime oxygen consumption rates. Rate 614 values with different letters are significantly different (one-way ANOVA followed by Tukey post 615 hoc tests; $\alpha=0.05)$.

616

617 Table 2: Statistical analysis of the effect of each oxygen treatment on the biological parameters 618 measured from algae and corals (one-way ANOVA). Significance of treatment on the effect was 619 tested on the difference in values of each parameter between experimental day 0 and 10 (Tukey 620 post hoc tests). Treatments with different letters indicate significant differences $(\alpha=0.05)$ in the 621 changes of the respective parameter.

623 Table S1: Results from two-way ANOVA analysis with the main effects of oxygen treatment (3624 levels) and species (2-levels) and their interaction on data measured using both coral and algae 625 (fluorescence analyses were excluded of this analysis because not shared by both species). 626 Statistically significant effects are shown in bold.

628 Table S2: Contribution (\%) that each of the studied factors (oxygen treatment, experimental time, 629 individual repeate, and individual repeate variation over time) has on the metrics of organism 630 health measured from the coral and algae. The residual indicates fraction of the contribution that 631 remains unexplained by the present factors. Each factor is associated with a different degree of 632 freedom (DF); statistically significant effects are shown in bold $(\mathrm{p}<0.05)$ and marked with an 633 asterisk when $\mathrm{p}<0.01$ (from Repeated Measures ANOVA). 


\section{Figure Legends}

646 Fig 1: Summary of responses from the coral A. yongei and alga B. pennata to the oxygen 647 treatments: 1.1) Photosynthetic oxygen production, 1.2) pulse amplitude modulation fluorescence 648 measurements of maximum (dark-adapted) quantum yield, 1.3) fraction of red pixels in images of 649 algal fluorescence, 1.4) green intensity, 1.5) fraction of green pixels, and 1.6) red intensity of 650 images taken from coral fluorescence. Panel A shows mean values ( \pm standard error) and a corresponding derived simple spline curve for each treatment over the $10 \mathrm{~d}$ experimental period.

652 Panel B - E show box plots (data range and mean value indicated by black line) of the deviation 653 to initial values for each measurement day $(\mathrm{B}=$ day $0-1, \mathrm{C}=$ day $0-3, \mathrm{D}=$ day $0-7, \mathrm{E}=$ day $6540-10)$.

655

656 Fig 2: Representative images of the coral A. yongei and the alga B. pennata in bright field (upper 657 panels) and fluorescence (lower panels) for two different oxygen treatments over the time of the 658 experiment. A. coral 6-8 mg L ${ }^{-1}$, B. coral 2-4 mg L-1, C. alga 6-8 mg L-1, D. alga 2-4 mg L-1.

660 Fig S1: Maximum and effective quantum yield values (QY) for coral specimen subjected to the 661 low oxygen treatment over the course of the experimental period. Individual coral specimens are 662 marked by color while the bold black lines indicate the average effective (dotted lines) and 663 maximum (solid lines) QY values. Note that only on experimental day 10 effective QY values are 664 always higher than maximum QY values. Lines represent a locally weighted scatterplot smoother, 665 i.e. Kernel Smoother.

666

667 Fig S2: Representative images of the coral A. yongei subjected to A.) $6-8 \mathrm{mg} \mathrm{L}^{-1}$, B.) $4-6 \mathrm{mg}$ $668 \mathrm{~L}^{-1}$, and C.) $2-4 \mathrm{mg} \mathrm{L}^{-1}$ in fluorescence. The pictures visualize the changes in brightness (i.e. 669 amount of GFPs) and distribution (i.e. coenosarc and polyps versus polyps mainly) of green 670 fluorescence. 


\section{Figure 1}

Summary of responses from the coral $A$. yongei and alga $B$. pennata to the oxygen treatments

Summary of responses from the coral $A$. yongei and alga B. pennata to the oxygen treatments: 1.1) Photosynthetic oxygen production, 1.2) pulse amplitude modulation fluorescence measurements of maximum (dark-adapted) quantum yield, 1.3) fraction of red pixels in images of algal fluorescence, 1.4) green intensity, 1.5) fraction of green pixels, and 1.6) red intensity of images taken from coral fluorescence. Panel A shows mean values ( \pm standard error) and a corresponding derived simple spline curve for each treatment over the $10 \mathrm{~d}$ experimental period. Panel $\mathrm{B}-\mathrm{E}$ show box plots (data range and mean value indicated by black line) of the deviation to initial values for each measurement day $(B=$ day $0-1, C=$ day $0-3, \mathrm{D}=$ day $0-7, \mathrm{E}=$ day $0-10$ ).

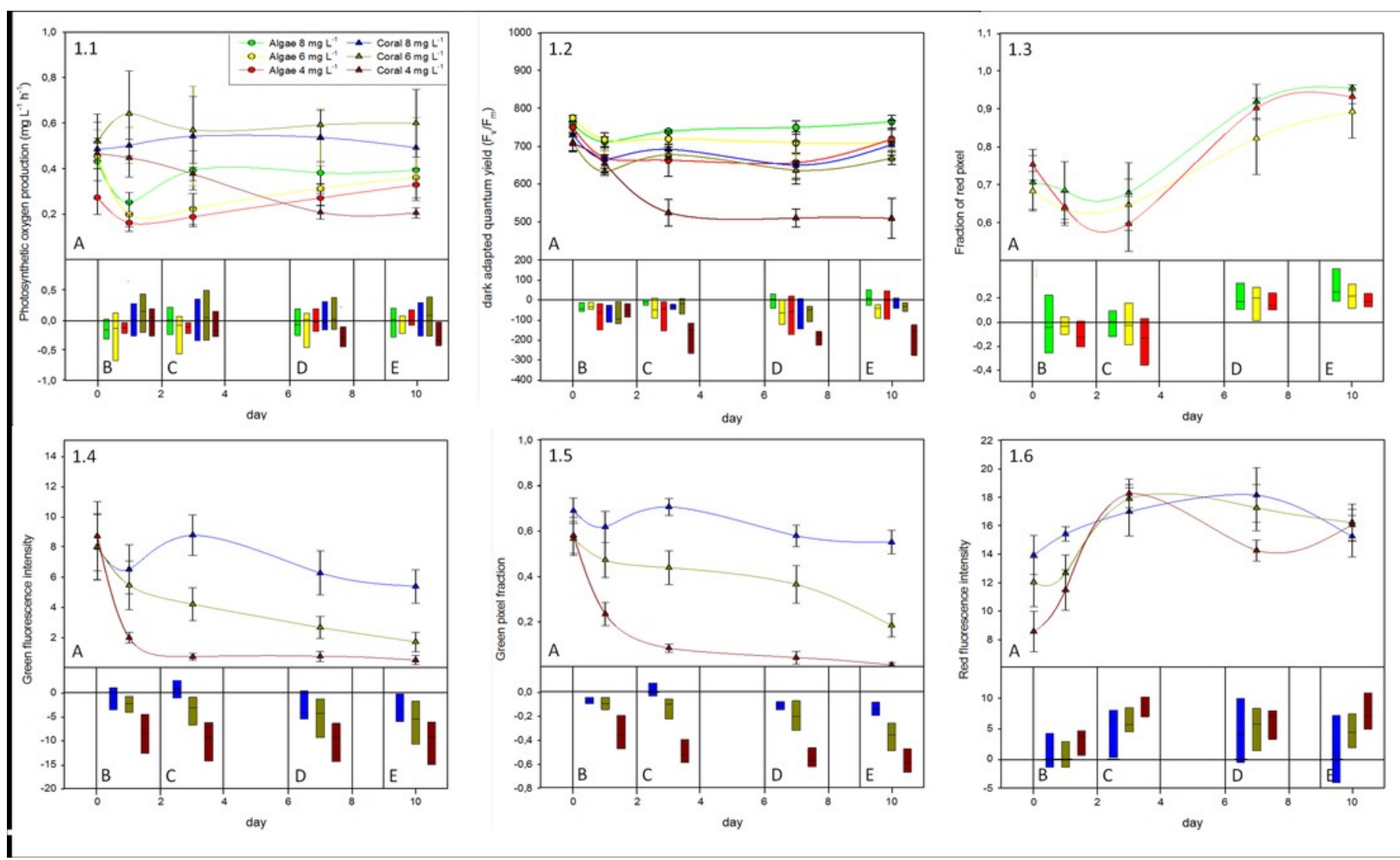




\section{Figure 2}

Fluorescence timeline

Representative images of the coral $A$. yongei and the alga B. pennata in bright field (upper panels) and fluorescence (lower panels) for two different oxygen treatments over the time of the experiment. A. coral 6-8 mg L $\mathrm{L}^{-1}$, B. coral 2-4 mg L-1, C. alga 6-8 $\mathrm{mg} \mathrm{L}^{-1}$, D. alga 2-4 mg L1. 

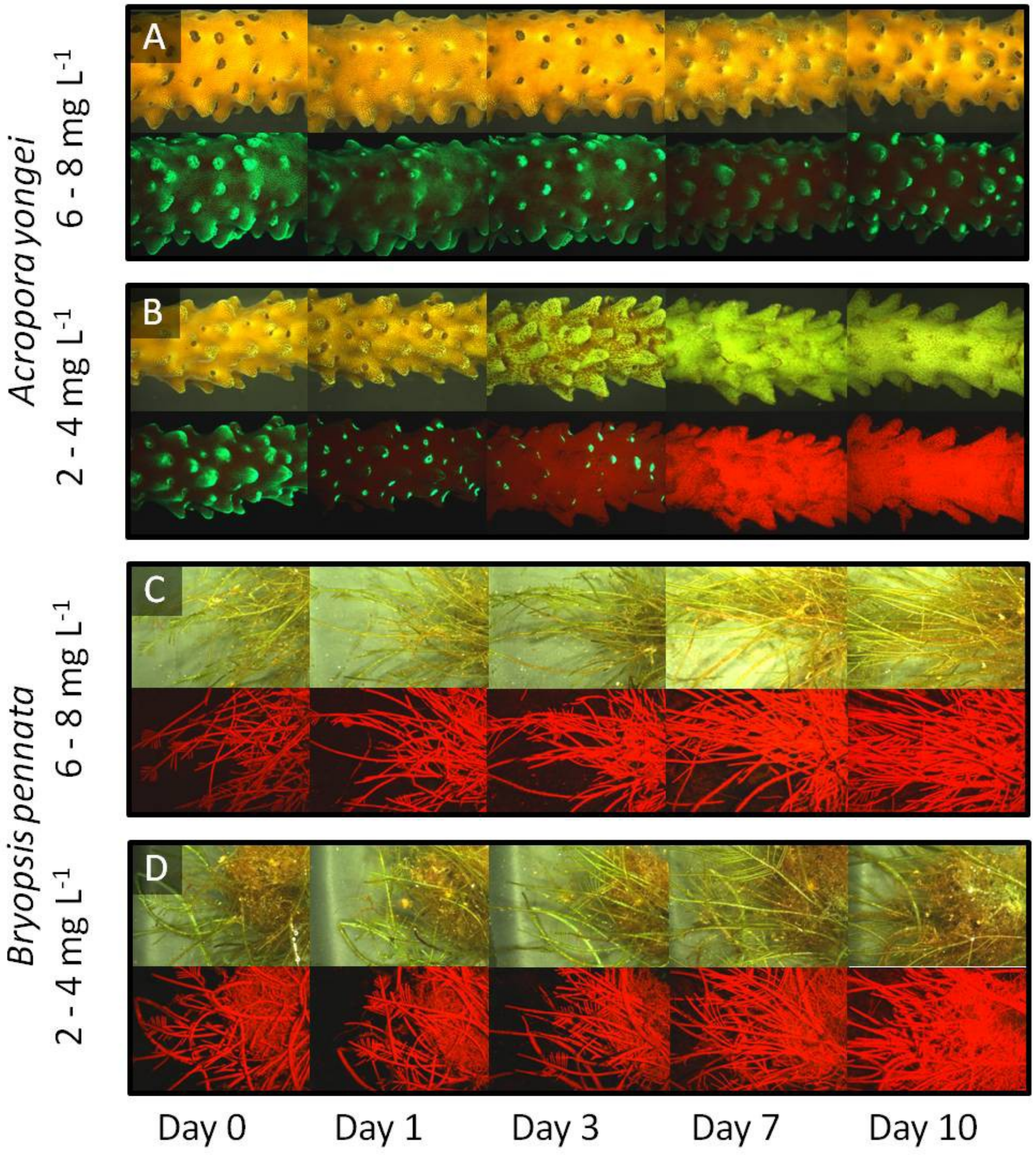


\section{Table 1 (on next page)}

Nighttime oxygen variations

Oxygen concentrations (mean \pm standard error) measured at start and end of nighttime oxygen treatments along with the corresponding nighttime oxygen consumption rates. Rate values with different letters are significantly different (one-way ANOVA followed by Tukey post hoc tests; $\alpha=0.05)$. 


\begin{tabular}{|c|c|c|c|}
\hline Treatment & DO start $\left(\mathrm{mg} \mathrm{L}^{-1}\right)$ & $\mathrm{DO}$ end $\left(\mathrm{mg} \mathrm{L}^{-1}\right)$ & $\mathrm{O}_{2}$ draw down $\left(\mathrm{mg} \mathrm{L}^{-1} \mathrm{~h}^{-1}\right)$ \\
\hline $\begin{array}{l}\text { Algae } 6-8 \mathrm{mg} \mathrm{L}^{-1} \\
\text { Algae } 4-6 \mathrm{mg} \mathrm{L}^{-1} \\
\text { Algae } 2-4 \mathrm{mg} \mathrm{L}^{-1}, \frac{\mathrm{O}}{2}\end{array}$ & $\begin{array}{l}7.99 \pm 0.01 \\
5.99 \pm 0.00 \\
4.01 \pm 0.01\end{array}$ & $\begin{array}{l}6.45 \pm 0.08 \\
4.51 \pm 0.14 \\
1.93 \pm 0.14 \\
\end{array}$ & $\begin{array}{l}0.13 \pm 0.007(A) \\
0.12 \pm 0.011(A) \\
0.17 \pm 0.011(B)\end{array}$ \\
\hline $\begin{array}{l}\text { Corals } 6-8 \mathrm{mg} \mathrm{L}^{-1} \\
\text { Corals } 4-6 \mathrm{mg} \mathrm{L}^{-1} \\
\text { Corals } 2-4 \mathrm{mg} \mathrm{L}^{-1} \frac{\mathrm{C}}{\rightleftharpoons}\end{array}$ & $\begin{array}{l}7.99 \pm 0.01 \\
5.99 \pm 0.00 \\
4.01 \pm 0.01\end{array}$ & $\begin{array}{l}6.45 \pm 0.06 \\
4.34 \pm 0.16 \\
1.98 \pm 0.08\end{array}$ & $\begin{array}{c}0.13 \pm 0.005(\mathrm{~A}) \\
0.14 \pm 0.013(\mathrm{~A}, \mathrm{~B}) \\
0.17 \pm 0.007(\mathrm{~B})\end{array}$ \\
\hline
\end{tabular}

$\frac{0}{3}$ 


\section{Table 2 (on next page)}

one-way ANOVA of the effect of oxygen treatments on the biological parameters

Statistical analysis of the effect of each oxygen treatment on the biological parameters measured from algae and corals (one-way ANOVA). Significance of treatment on the effect was tested on the difference in values of each parameter between experimental day 0 and 10 (Tukey post hoc tests). Treatments with different letters indicate significant differences $(\alpha=$ $0.05)$ in the changes of the respective parameter. 


\begin{tabular}{|c|c|c|c|c|c|c|c|c|c|c|c|}
\hline \multirow{2}{*}{ Group } & \multirow{2}{*}{$\begin{array}{c}\mathrm{O} 2 \\
\text { treatment }\end{array}$} & \multicolumn{2}{|c|}{$\mathrm{O} 2$ production } & \multicolumn{2}{|c|}{ Maximum QY } & \multicolumn{2}{|c|}{ Effective QY } & \multicolumn{2}{|c|}{ Green intensity $\mathrm{x}$ fraction } & \multicolumn{2}{|c|}{ Red intensity } \\
\hline & & ANOVA & Tukey & ANOVA & Tukey & ANOVA & Tukey & ANOVA & Tukey & ANOVA & Tukey \\
\hline \multirow{3}{*}{ Algae } & $6-8 \mathrm{mg} \mathrm{L}$ & \multirow{3}{*}{ 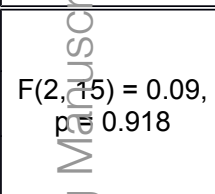 } & A & \multirow{3}{*}{$\begin{array}{c}F(2,15)=0.94 \\
p=0.411\end{array}$} & A & \multirow{3}{*}{$\begin{array}{c}F(2,15)=0.66 \\
p=0.530\end{array}$} & A & \multirow{3}{*}{ * } & \multirow{3}{*}{ * } & \multirow{3}{*}{ * } & \multirow{3}{*}{ * } \\
\hline & $4-6 \mathrm{mg} \mathrm{L}$ & & A & & A & & A & & & & \\
\hline & $2-4 \mathrm{mg} \mathrm{L}$ & & A & & A & & A & & & & \\
\hline \multirow{3}{*}{ Coral } & $6-8 \mathrm{mg} \mathrm{L}$ & \multirow{3}{*}{ 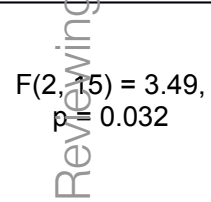 } & A & \multirow{3}{*}{$\begin{array}{c}F(2,15)=12.63 \\
p<0.001\end{array}$} & A & \multirow{3}{*}{$\begin{array}{c}F(2,15)=4.29 \\
p=0.037\end{array}$} & $A, B$ & \multirow{3}{*}{$\begin{array}{c}F(2,14)=39.73 \\
p<0.001\end{array}$} & A & \multirow{3}{*}{$\begin{array}{c}F(2,15)=5.76 \\
p=0.014\end{array}$} & A \\
\hline & $4-6 \mathrm{mg} \mathrm{L}$ & & A & & A & & $A$ & & B & & $A, B$ \\
\hline & $2-4 \mathrm{mg} \mathrm{L}$ & & B & & B & & B & & C & & B \\
\hline
\end{tabular}

*Green fluorescence wa ot measured for algae and red fluorescence was only considered as the fraction of red pixels used as a proxy for size. 